\title{
Pushing the Band Gap Envelope of Quasi-Type II Heterostructured Nanocrystals to Blue: $\mathrm{ZnSe} / \mathrm{ZnSe}_{1-X} \mathrm{Te}_{X} / \mathrm{ZnSe}$ Spherical Quantum Wells
}

\author{
Jun Hyuk Chang $\mathbb{D}^{1}$, Hak June Lee, ${ }^{2}$ Seunghyun Rhee $\mathbb{D}^{1},{ }^{1}$ Donghyo Hahm, ${ }^{1}$ \\ Byeong Guk Jeong $\mathbb{D}^{1}{ }^{1}$ Gabriel Nagamine, ${ }^{3}$ Lazaro A. Padilha $\mathbb{D}^{3}{ }^{3}$ Kookheon Char, \\ Euyheon Hwang, ${ }^{1}$ and Wan Ki Bae ${ }^{1}{ }^{1}$ \\ ${ }^{1}$ SKKU Advanced Institute of Nano Technology, Sungkyunkwan University, Suwon 16419, Republic of Korea \\ ${ }^{2}$ School of Chemical and Biological Engineering, Seoul National University, Seoul 08826, Republic of Korea \\ ${ }^{3}$ Instituto de Fisica “Gleb Wataghin”, Universidade Estadual de Campinas, UNICAMP, P.O. Box 6165, 13083-859 Campinas, \\ São Paulo, Brazil
}

Correspondence should be addressed to Wan Ki Bae; wankibae1@gmail.com

Received 20 August 2020; Accepted 23 September 2020; Published 5 February 2021

Copyright ( 2021 Jun Hyuk Chang et al. Exclusive Licensee Beijing Institute of Technology Press. Distributed under a Creative Commons Attribution License (CC BY 4.0).

\begin{abstract}
Quasi-type II heterostructured nanocrystals (NCs) have been of particular interest due to their great potential for controlling the interplay of charge carriers. However, the lack of material choices for quasi-type II NCs restricts the accessible emission wavelength from red to near-infrared (NIR), which hinders their use in light-emitting applications that demand a wide range of visible colors. Herein, we demonstrate a new class of quasi-type II nanoemitters formulated in $\mathrm{ZnSe}_{\mathrm{ZnSe}} \mathrm{In}_{1} \mathrm{Te}_{X} / \mathrm{ZnSe}$ seed/spherical quantum well/shell heterostructures (SQWs) whose emission wavelength ranges from blue to orange. In a given geometry, $\mathrm{ZnSe}_{1-X} \mathrm{Te}_{X}$ emissive layers grown between the $\mathrm{ZnSe}$ seed and the shell layer are strained to fit into the surrounding media, and thus, the lattice mismatch between $\mathrm{ZnSe}_{1-X} \mathrm{Te}_{X}$ and $\mathrm{ZnSe}$ is effectively alleviated. In addition, composition of the $\mathrm{ZnSe}_{1-X} \mathrm{Te}_{X}$ emissive layer and the dimension of the ZnSe shell layer are engineered to tailor the distribution and energy of electron and hole wave functions. Benefitting from the capabilities to tune the charge carriers on demand and to form defectfree heterojunctions, $\mathrm{ZnSe} / \mathrm{ZnSe}_{1-X} \mathrm{Te}_{X} / \mathrm{ZnSe} / \mathrm{ZnS}$ NCs show near-unity photoluminescence quantum yield (PL QY $\left.>90 \%\right)$ in a broad range of emission wavelengths (peak PL from $450 \mathrm{~nm}$ to $600 \mathrm{~nm}$ ). Finally, we exemplify dichromatic white NC-based light-emitting diodes (NC-LEDs) employing the mixed layer of blue- and yellow-emitting $\mathrm{ZnSe}_{\mathrm{ZnSe}} \mathrm{ZTe}_{X} / \mathrm{ZnSe} / \mathrm{ZnS} \mathrm{SQW} \mathrm{NCs}$.
\end{abstract}

\section{Introduction}

Colloidal semiconductor nanocrystals (NCs), in which charge carriers are confined in all three dimensions, have received tremendous interest as next-generation lightemissive materials owing to their unique optical properties such as broad absorption but narrow emission bandwidth and size-dependent band gap tunability across visible to near IR [1-4]. In addition to the quantum confinement effect, the heterojunction in NCs enables further control over the spatial distribution of charge carriers and their dynamics, boosting practicable use of NCs in displays [5-7], luminescent solar concentrators (LSCs) $[8,9]$, and biomarkers [10]. The representative is the core/shell heterostructures, wherein the charge carriers in the core are decoupled from the surface trap states to award photochemical stability and near-unity luminescence efficiency at room temperature [11-13].

Among the core/shell heterostructures, NCs with the quasi-type II band alignment have been of particular interest due to their great potential for controlling the interactions among charge carriers. In quasi-type II heterostructured $\mathrm{NCs}$, one charge carrier is confined in the core, whereas the other charge carrier is delocalized over the entire volume, thus controlling the geometry or the dimension of the core, and the shell allows managing the electron and hole wave functions independently. The distinguished feature of quasi-type II heterostructured NCs is the suppression of nonradiative Auger recombination processes of multicarriers 
(more than one electron and one hole) [14-16], which is the key to high efficiency light-emitting diodes and low threshold lasers.

To achieve quasi-type II NC emitters, two semiconductor materials having similar conduction band edge (CBE) energy levels or valence band edge (VBE) energy level need to form a contact without the interfacial defects. So far, reports on quasi-type II NCs have been limited to few cases (i.e., CdSe/CdS [15-18], PbSe/CdSe [19], and $\mathrm{CuInS}_{2} / \mathrm{CdS}$ [20, 21]). The lack of materials choice for quasi-type II NCs restricts the accessible emission wavelength from red to NIR, which in return hinders their use in light-emitting applications that demand a wide range of visible colors.

Herein, we demonstrate a new class of quasi-type II nanoemitters formulated in $\mathrm{ZnSe} / \mathrm{ZnSe}_{1-X} \mathrm{Te}_{X} / \mathrm{ZnSe}$ seed/spherical quantum well/shell heterostructures (SQWs). The composition of the $\mathrm{ZnSe}_{1-X} \mathrm{Te}_{X}$ emissive layer and the dimension of the ZnSe shell layer are engineered to tailor the distribution and energy of hole and electron wave functions and their interactions. In addition, a comprehensive study across spectroscopic analysis, structural analysis, and calculation is conducted to assess the role of the composition and the geometry of given SQW NCs on their photophysical properties. Finally, we exemplify dichromatic white lightemitting diodes enabled by excellent luminescence efficiency of resulting SQW NCs in a range of emission colors from blue to orange.

\section{Materials and Methods}

2.1. Materials. Zinc acetate $\left(\mathrm{Zn}(\mathrm{ac})_{2}, 99.99 \%\right)$, selenium (Se, $99.9 \%)$, sulfur $\left(\mathrm{S}_{8}, 99.9 \%\right)$, oleic acid (OA, 99\%), ntrioctylphosphine (TOP, 99\%), and 1-octadecene (ODE, 99\%) were purchased from Uniam. Diphenylphosphine (DPP, 98\%), zinc acetate dihydrate $\left(\mathrm{Zn}(\mathrm{ac})_{2} \cdot 2 \mathrm{H}_{2} \mathrm{O}, \geq 98 \%\right)$, 1-dodecanethiol (DDT, 98\%), potassium hydroxide $(\mathrm{KOH}$, 90\%), and butylamine (99.5\%) were purchased from Aldrich. Tellurium powder (Te, 99.999\%) was purchased from Alfa Aesar. Poly[(9,9-bis(3'-(N,N-dimethylamino)propyl)-2,7fluorene)-alt-2,7-(9,9-ioctylfluorene)] (PFN) was purchased from 1-Material. 2,2' -Bis(4-(carbazol-9-yl)phenyl)-biphenyl (BCBP, >99.9\%) was purchased from Organic Semiconductor Materials (OSM, Korea). $\mathrm{MoO}_{3}$ and $\mathrm{Al}$ were purchased from iTASCO (Korea). All chemicals are used as received.

2.2. Synthesis of $\mathrm{ZnSe} / \mathrm{ZnS} e_{1-X} T e_{X}$ Seed/Emissive Layer Structure. All syntheses were carried out under the inert atmosphere through the Schlenk line technique. $1.2 \mathrm{ml}$ of $0.5 \mathrm{M} \mathrm{Zn}(\mathrm{OA})_{2}$ prepared from $\mathrm{Zn}(\mathrm{ac})_{2}$, OA and $\mathrm{ODE}$, and $15 \mathrm{ml}$ of $\mathrm{ODE}$ were stirred and degassed at $110^{\circ} \mathrm{C}$ in a 3 neck round flask. After one hour of degassing to remove water and oxygen completely, it was filled with $\mathrm{N}_{2}$. Then, $1 \mathrm{ml}$ of $0.2 \mathrm{M}$ DPPSe, prepared from $4 \mathrm{mmol}$ Se powder, $2 \mathrm{ml} \mathrm{DPP}$, and $18 \mathrm{ml}$ anhydrous toluene, was injected at $230^{\circ} \mathrm{C}$, and after 1 minute, the $\mathrm{ZnSe}$ seed is synthesized $(r=0.6 \mathrm{~nm}) ; 0.5 \mathrm{M}$ TOPTe $(0.02 \mathrm{ml}(X=0.03), 0.06 \mathrm{ml}$ $(X=0.1), 0.12 \mathrm{ml}(X=0.2), 0.2 \mathrm{ml}(X=0.33)$, and $0.3 \mathrm{ml}$ $(X=0.5))$, prepared from $50 \mathrm{mmol}$ Te powder and $100 \mathrm{ml}$ TOP, and $2 \mathrm{M}$ TOPSe $(0.145 \mathrm{ml}(X=0.03), 0.135 \mathrm{ml}$
$(X=0.1), 0.12 \mathrm{ml}(X=0.2), 0.1 \mathrm{ml}(X=0.33)$, and $0.075 \mathrm{ml}$ $(X=0.5))$ were injected to grow the $\mathrm{ZnSe}_{1-X} \mathrm{Te}_{X}$ emissive layer at the same temperature and maintained for 30 minutes. After that, the reaction temperature was increased to $300^{\circ} \mathrm{C}$ for $15 \mathrm{~m}$ to grow seed/emissive layer completely $(r=0.6 \mathrm{~nm}, l=1.2 \mathrm{~nm})$.

2.3. Synthesis of $Z n S e / Z n S e_{1-X} T e_{X} / Z n S e$ and $Z n S e / Z n S e_{1-}$ ${ }_{X} \mathrm{Te}_{X} / \mathrm{ZnSe} / \mathrm{ZnS} \mathrm{NCs}$. ZnSe/ZnSe ${ }_{1-X} \mathrm{Te}_{X} / \mathrm{ZnSe}$ NCs were synthesized by injecting additional precursor to grow the $\mathrm{ZnSe}$ outer shell; at the first $\mathrm{ZnSe}$ shell, $2 \mathrm{ml} \mathrm{Zn(OA)})_{2}(0.5 \mathrm{M}$ stock solution) and $0.25 \mathrm{ml}$ TOPSe ( $2 \mathrm{M}$ stock solution) were injected and maintained at $320^{\circ} \mathrm{C}$ for 30 minutes ( $r=0.6 \mathrm{~nm}, l=1.2 \mathrm{~nm}$, and $h=0.6 \mathrm{~nm})$. For the consecutive thick $\mathrm{ZnSe}$ outer shell growth, $\mathrm{Zn}(\mathrm{OA})_{2} 3.4,5.2$, and $7.8 \mathrm{ml}$ and TOPSe $0.425,0.625$, and $0.975 \mathrm{ml}$ were injected in sequence at $320^{\circ} \mathrm{C}$ for 60 minutes per each step $(r=0.6 \mathrm{~nm}$, $l=1.2 \mathrm{~nm}$, and $h=1.2,1.8$, and $2.4 \mathrm{~nm}$ ). To the passivate surface trap, a thin $\mathrm{ZnS}$ shell was grown on $\mathrm{ZnSe} / \mathrm{ZnSe}_{1}$ ${ }_{X} \mathrm{Te}_{X} / \mathrm{ZnSe}(r=0.6 \mathrm{~nm}, l=1.2 \mathrm{~nm}$, and $h=0.6,1.2,1.8$, and $2.4 \mathrm{~nm}$ ) by the same process but with different amounts of precursors. $\mathrm{Zn}(\mathrm{OA})_{2} 3.4,5.2,7.8$, and $10 \mathrm{ml}$ and DDT 0.2, $0.3,0.45$, and $0.58 \mathrm{ml}$ were injected, respectively, to different outer ZnSe shell thickness NCs at $300^{\circ} \mathrm{C}$ for 60 minutes. Synthesized NCs were purified repeatedly in a glove box via the precipitation (30 $\mathrm{ml}$ of acetone)/redispersion ( $10 \mathrm{ml}$ of anhydrous toluene) method, diluted at a concentration of $20 \mathrm{~g} / \mathrm{ml}$ (anhydrous toluene) and kept in glove box refrigerator for device fabrication and UPS measurement.

2.4. Device Fabrication. Before $\mathrm{ZnSe} / \mathrm{ZnSe}_{1-X} \mathrm{Te}_{X} / \mathrm{ZnSe} \mathrm{NC}-$ LED fabrication, patterned indium tin oxide (ITO) glass substrates were cleaned with acetone, isopropyl alcohol, and deionized water for $15 \mathrm{~min}$. First, $\mathrm{ZnO} \mathrm{NP}$ solution $(20 \mathrm{mg} / \mathrm{ml}$ in butanol) was spun-cast on an ITO substrate at a spin rate of $2000 \mathrm{rpm}$ for 40 seconds followed by annealing at $100^{\circ} \mathrm{C}$ for $30 \mathrm{~min}$. Afterwards, PFN solution $(0.5 \mathrm{mg} / \mathrm{ml}$ in methanol/acetic acid mixed solvent) was spun-cast on the $\mathrm{ZnO}$-coated substrates at a spin rate of $4000 \mathrm{rpm}$ for $30 \mathrm{sec}-$ onds. The PFN-coated substrates were dried for 30 minutes under vacuum condition. $\mathrm{ZnSe} / \mathrm{ZnSe}_{1-X} \mathrm{Te}_{X} / \mathrm{ZnSe} / \mathrm{ZnS} \mathrm{NC}$ solutions $(10 \mathrm{mg} / \mathrm{ml}$ in toluene) were spun-cast at $4000 \mathrm{rpm}$ for 30 seconds to form 2-3 monolayers of NCs. Finally, BCBP $(60 \mathrm{~nm}), \mathrm{MoO}_{3}(10 \mathrm{~nm})$, and $\mathrm{Al}(130 \mathrm{~nm})$ layers were thermally evaporated under a vapor pressure of $1 \times 10^{-6}$ Torr. The deposition rates of each layer were $0.5-1 \AA /$ s for BCBP, 0.1-0.2 $\AA$ /s for $\mathrm{MoO}_{3}$, and 3-5 $\mathrm{A} / \mathrm{s}$ for $\mathrm{Al}$.

2.5. Optical and Structural Characterization. Absorption and photoluminescence spectra were obtained with a Shimadzu UV-1800 and Horiba FluoroMax-4, respectively. Absolute PL QY was measured with an Otsuka QE-2000 at the same absorbance (0.1) in toluene with the $450 \mathrm{~nm}$ excitation wavelength. High-resolution TEM images were obtained from a FEI Tecnai F20. The current-voltage-luminance (I-V-L) characteristics of the NC-LEDs were measured using a Keithley-236 source-measure unit and a Keithley-2000 multimeter with a calibrated $\mathrm{Si}$ photodiode (Hamamatsu, S5227-1010BQ). The electroluminescence spectra of the 
devices were obtained by a spectroradiometer (Konica Minolta, CS-2000).

The crystalline structures of NCs were investigated by synchrotron X-ray diffraction measurements (JP/D/MAX$2500 \mathrm{H}, \mathrm{X}$ - ray wavelength $=1.5406 \AA$ ) The XRD data were acquired in the $2 \theta$ range between $20^{\circ}$ and $60^{\circ}$ at a scan rate of $1^{\circ} /$ min. The XRD patterns of $\mathrm{ZnSe}$ and $\mathrm{ZnSe}_{1-X} \mathrm{Te}_{X}$ in $\mathrm{ZnSe} / \mathrm{ZnSe}_{1-X} \mathrm{Te}_{X} \mathrm{NCs}$ were decoupled by subtracting a separately measured XRD pattern of ZnSe NCs from that of $\mathrm{ZnSe}_{\mathrm{ZnSe}} \mathrm{IX}_{X} \mathrm{Te}$ NCs, considering the volume of each component.

\section{Results and Discussion}

As a new class of quasi-type II NCs, we construct heterojunctions made of $\mathrm{ZnSe}_{1-X} \mathrm{Te}_{X}$ emissive layer passivated by a $\mathrm{ZnSe}$ shell layer for the following reasons. First, the band gap of $\mathrm{ZnSe}_{1-X} \mathrm{Te}_{X}$ bulk semiconductors can cover a wide range of visible regions, from blue to orange, depending on the alloy compositions. In addition, the energy offset between conduction band edge energy levels (ECBE) of $\mathrm{ZnSe}$ and $\mathrm{ZnSe}_{1-X} \mathrm{Te}_{X}$ is similar to the thermal energy of room temperature $(\mathrm{kBT}=25 \mathrm{meV})$, allowing the electron wave function to spread over the entire volume of NCs. Furthermore, the crystal structures of $\mathrm{ZnSe}$ and $\mathrm{ZnTe}$ are both zincblende, and thus, the epitaxial growth of $\mathrm{ZnSe}$ on $\mathrm{ZnSe}_{1-X} \mathrm{Te}_{X}$ is achievable.

Heterostructuring $\mathrm{ZnSe}_{1-X} \mathrm{Te}_{X}$ and $\mathrm{ZnSe}$ in a conventional core/shell geometry entails the nucleation of the $\mathrm{ZnSe}_{1-X} \mathrm{Te}_{X}$ emissive core and the epitaxial growth of the ZnSe shell, but both appear to be challenging to be experimentally realized via wet-chemistry. First, the significant reactivity difference between $\mathrm{Se}$ and Te precursors often results in the independent nucleation of $\mathrm{ZnSe}$ and $\mathrm{ZnTe}$ instead of the formation of a homogeneous $\mathrm{ZnSe}_{1-X} \mathrm{Te}_{X}$ core, particularly at high $\mathrm{Te}$ contents $(X \geq 0.30)$ (Figure $\mathrm{S} 1$ ). In addition, the large lattice mismatch between the $\mathrm{ZnSe}_{1}$. ${ }_{X} \mathrm{Te}_{X}$ emissive core and the $\mathrm{ZnSe}$ shell promotes the creation of misfit defects at the interface, which gives rise to the reduction of PL QYs with increasing shell thicknesses [22]. The difficulties in the synthesis of homogenous $\mathrm{ZnSe}_{1-}$ ${ }_{X} \mathrm{Te}_{X}$ emissive cores and defect-free growth of the $\mathrm{ZnSe}$ shell on $\mathrm{ZnSe}_{1-X} \mathrm{Te}_{X}$ impedes the realization of high quality $\mathrm{ZnSe}_{1-X} \mathrm{Te}_{X} / \mathrm{ZnSe}$ core/shell heterostructured NCs with varying Te contents [23-25].

As a mean to relieve the structural stress between the $\mathrm{ZnSe}_{1-X} \mathrm{Te}_{X}$ emissive layer and the $\mathrm{ZnSe}$ shell, we adopt the concept of coherently strained multilayered heterostructures [26]. Specifically, we design the $\mathrm{ZnSe} / \mathrm{ZnSe}_{1-X} \mathrm{Te}_{X} / \mathrm{ZnSe}$ seed/spherical quantum well/shell heterostructures (Figure 1(a)), in which the $\mathrm{ZnSe}_{1-X} \mathrm{Te}_{X}$ emissive layer is successively grown on top of the $\mathrm{ZnSe}$ seed and passivated by the ZnSe shell layer. In a SQW geometry, the sandwiched emissive layer is strained by the presence of an underlying seed to relieve the structural stress against the shell layer, enabling to attain high luminescence efficiency even with thick shells $[26,27]$. Besides, the growth of the $\mathrm{ZnSe}_{1-X} \mathrm{Te}_{X}$ emissive layer requires the injection of mixed Se and Te precursors at the concentration below the critical concentration for nucleation of $\mathrm{ZnSe}$ and $\mathrm{ZnTe}$, which allows to avoid the problems that originated from the inhomogeneity in size and composition among NCs.

As a first step, we optimize the reaction condition for the synthesis of ZnSe seeds with a radius $(r)$ of $0.6 \mathrm{~nm}$ and further $\mathrm{ZnSe}$ growth up to $1.8 \mathrm{~nm}$ (Figure S2). At the given homoepitaxy growth condition, we replace in part the Se precursor with the Te precursor to grow the $\mathrm{ZnSe}_{1-X} \mathrm{Te}_{X}$ emissive layer. Resulting NCs show uniform size distribution (std 10\%) and single Gaussian PL emission regardless of Te contents. Small particles or side PL peaks, which are the signs of homogenous nucleation of $\mathrm{ZnSe}$ or $\mathrm{ZnTe}$, do not appear during the growth (Figure S3). The composition analysis in chorus with the size and shape monitoring confirms that the Te content $(X)$ of the $\mathrm{ZnSe}_{1}$ ${ }_{X} \mathrm{Te}_{X}$ emissive layer remains unchanged along the radial direction (Figure S4). These results coherently attest to the successive growth of homogeneous $\mathrm{ZnSe}_{1-X} \mathrm{Te}_{X}$ emissive layers on the surface of $\mathrm{ZnSe}$ seeds. The sequential growth of $\mathrm{ZnSe}$ on top of $\mathrm{ZnSe} / \mathrm{ZnSe}_{1-X} \mathrm{Te}_{X} \mathrm{NCs}$ at the given reaction condition results in $\mathrm{ZnSe} / \mathrm{ZnSe}_{1-X} \mathrm{Te}_{X} / \mathrm{ZnSe} S \mathrm{SQ}$ NCs.

Figure 1 shows the structure and optical properties of the resulting $\mathrm{ZnSe} / \mathrm{ZnSe}_{1-X} \mathrm{Te}_{X} / \mathrm{ZnSe} S Q W$ NCs. In such a geometry, the hole is strongly confined within the $\mathrm{ZnSe}_{1-X} \mathrm{Te}_{X}$ emissive layer, whereas the electron is delocalized over the entire volume of the $\mathrm{ZnSe} / \mathrm{ZnSe}_{1-X} \mathrm{Te}_{X} / \mathrm{ZnSe} \mathrm{SQW} \mathrm{NCs}$ (Figure 1(c)). The dimensions of the $\mathrm{ZnSe}$ seed (radius, $r$ ) and the $\mathrm{ZnSe}_{1-X} \mathrm{Te}_{X}$ emissive layer (thickness, $l$ ) are fixed to be $r=0.6 \mathrm{~nm}$ and $l=1.2 \mathrm{~nm}$ for all samples, and thus, the variation in the $\mathrm{ZnSe}$ shell thickness $(h)$ determines the distribution of the electron wave function and its energy. By contrast, the hole wave function is solely affected by the composition of the $\mathrm{ZnSe}_{1-X} \mathrm{Te}_{X}$ emissive layer $(X)$. Engineering these parameters permits to tune the emission wavelength of heterostructured NCs from blue (peak PL at $450 \mathrm{~nm}$ ) to orange (peak PL at $600 \mathrm{~nm}$ ) (Figures 1(b) and 1(d)).

A notable feature of the resulting NCs is the excellence in PL QYs. Specifically, passivating additional thin $\mathrm{ZnS}$ shell layer $(0.6 \mathrm{~nm})$ on the exterior of $\mathrm{ZnSe} / \mathrm{ZnSe}_{1-X} \mathrm{Te}_{X} / \mathrm{ZnSe}$ SQW NCs assists in diminishing the influence of surface trap states on the charge carrier wave functions, resulting in over 90\% PL QY of NCs even in cases with high Te content

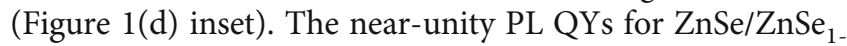
${ }_{X} \mathrm{Te}_{X} / \mathrm{ZnSe} / \mathrm{ZnS} \mathrm{SQW}$ NCs clearly contrast with previous reports on $\mathrm{ZnSe}_{1-X} \mathrm{Te}_{X} / \mathrm{ZnSe} / \mathrm{ZnS}$ core/shell NCs with similar structural parameters (PLQY $=52 \%$ for $X=0.02$, ZnSe shell thickness $=1.5 \mathrm{~nm}$, and $\mathrm{ZnS}$ shell thickness $=0.4 \mathrm{~nm}$ ) [22], which in turn implies that the formation of misfit defects at the interface between the $\mathrm{ZnSe}_{1-X} \mathrm{Te}_{X}$ emissive layer and $\mathrm{ZnSe}$ surround media is effectively suppressed in the SQW platform.

To validate the impact of the geometry on the lattice strain relaxation between $\mathrm{ZnSe}_{1-X} \mathrm{Te}_{X}$ and $\mathrm{ZnSe}$, we characterize the lattice constant of $\mathrm{ZnSe}_{1-X} \mathrm{Te}_{X}$ emissive layers grown on ZnSe seeds (Figure 2). We obtain the X-ray diffraction patterns of $\mathrm{ZnSe} / \mathrm{ZnSe}_{1-X} \mathrm{Te}_{X}$ seed/spherical quantum well samples and decouple the contribution of ZnSe seeds to extract the patterns of $\mathrm{ZnSe}_{1-X} \mathrm{Te}_{X}$ only (see Section 2.5). $\mathrm{ZnSe}_{1-X} \mathrm{Te}_{X}$ films are well-known to follow Vegard's law in 


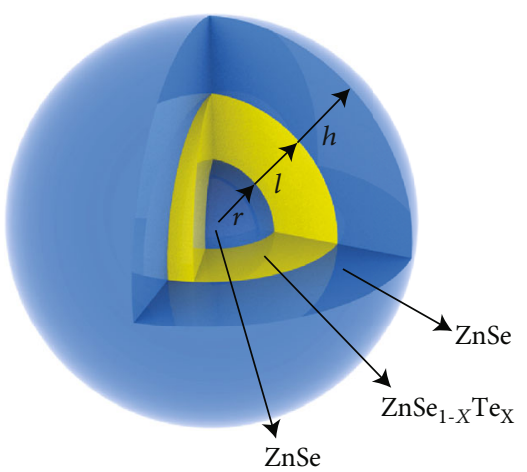

(a)

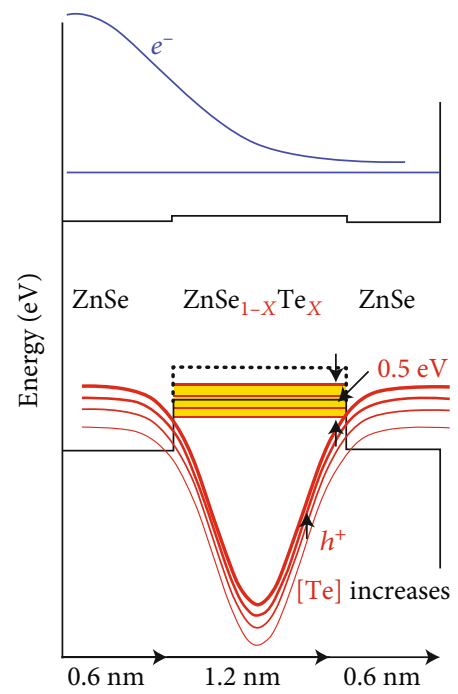

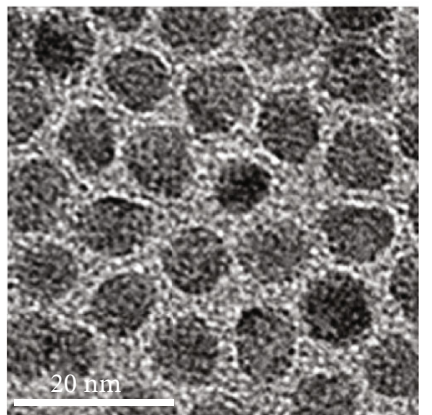

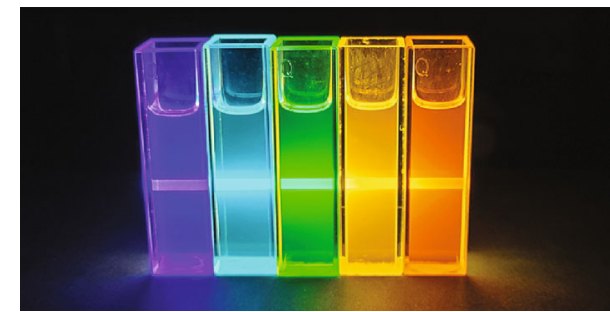

(b)

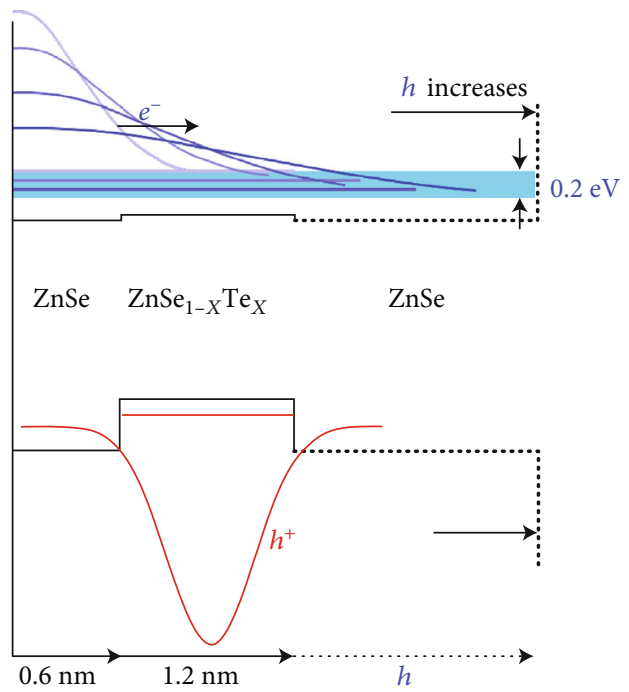

(c)

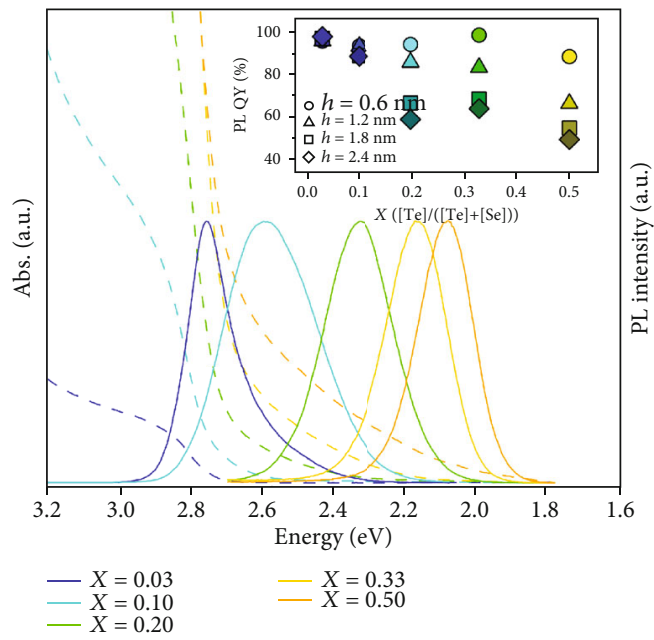

(d)

Figure 1: Structural characteristics and optical properties of $\mathrm{ZnSe} / \mathrm{ZnSe}_{1-X} \mathrm{Te}_{X} / \mathrm{ZnSe} \mathrm{SQW}$ NCs. (a) Schematic illustration (left) and transmission electron microscopy (TEM) image (right) of ZnSe $(r=0.6 \mathrm{~nm}) / \mathrm{ZnSe}_{1-X} \mathrm{Te}_{X}(l=1.2 \mathrm{~nm}) / \mathrm{ZnSe}(h=2.4 \mathrm{~nm}) \mathrm{NCs}$. Scale bar is $20 \mathrm{~nm}$. (b) A photographic image of $\mathrm{ZnSe}(r=0.6 \mathrm{~nm}) / \mathrm{ZnSe}_{1-X} \mathrm{Te}_{X}(l=1.2 \mathrm{~nm}) / \mathrm{ZnSe}(h=2.4 \mathrm{~nm}) \mathrm{NC}$ dispersions with varying Te ratios.

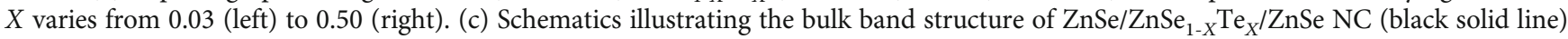
and electron (blue) and hole (red) wave function at their lowest quantized energy state. The change in Te content $(X)$ alters the energy states for the hole (left), whereas the modulation of $\mathrm{ZnSe}$ shell thickness alters the energy states for electron (right). (d) Absorption (dashed line) and PL spectra (solid line) of $\mathrm{ZnSe}(r=0.6 \mathrm{~nm}) / \mathrm{ZnSe}_{1-X} \mathrm{Te}_{X}(l=1.2 \mathrm{~nm}) / \mathrm{ZnSe}$ NCs with varying Te ratios $(0.03 \leq X \leq 0.50)$ and ZnSe shell thicknesses $(0 \leq h \leq 2.4 \mathrm{~nm})$. The inset displays PL QYs of $\mathrm{ZnSe} / \mathrm{ZnSe}_{1-X} \mathrm{Te}_{X} / \mathrm{ZnSe} \mathrm{NCs}$ with varying Te contents $(0.03 \leq X \leq 0.50)$ and ZnSe shell thicknesses $(h=0.6,1.2,1.8$, and $2.4 \mathrm{~nm})$. 


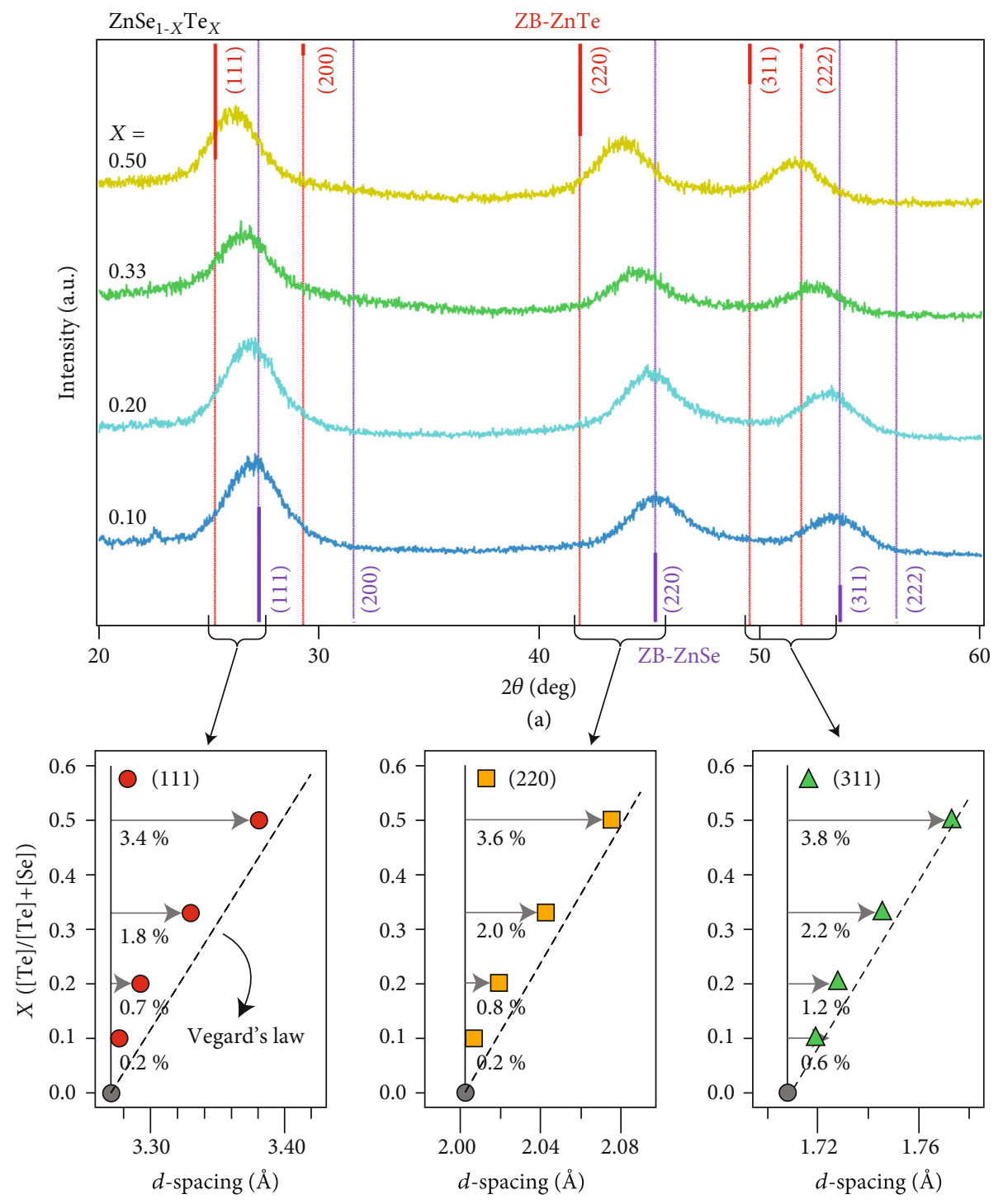

(b)

Figure 2: Lattice strain relaxation in $\mathrm{ZnSe} / \mathrm{ZnSe}_{1-X} \mathrm{Te}_{X} / \mathrm{ZnSe} \mathrm{SQW}$ NCs. (a) XRD patterns of $\mathrm{ZnSe}_{1-X} \mathrm{Te}_{X}$ emissive layers with varying Te contents ( $X$ varies from 0.10 (bottom) to 0.50 (top)). The XRD patterns of $\mathrm{ZnSe}_{1-X} \mathrm{Te}_{X}$ and $\mathrm{ZnSe}$ in $\mathrm{ZnSe} / \mathrm{ZnSe}{ }_{1-X} \mathrm{Te}_{X} \mathrm{NCs}$ were decoupled by subtracting separately measured XRD patterns of the ZnSe seed from that of $\mathrm{ZnSe} / \mathrm{ZnSe} e_{1-X} \mathrm{Te}_{X} \mathrm{NCs}$, by considering the volume of each component. The XRD patterns are vertically shifted for visual clarity. The characteristic diffraction peaks of bulk zincblende ZnSe (violet, bottom, JCPDS No. 65-9602) and ZnTe (red, top, JCPDS No. 15-0746) are displayed for comparison. (b) $d$ spacing for (111) (red circle (left)), (220) (orange square (middle)), and (311) (green triangle (right)) peaks and the estimated $d$-spacing of bulk $\mathrm{ZnSe}_{1-X} \mathrm{Te}_{X}$ alloys from Vegard's law (black broken line) are displayed for comparison.

a wide range of alloy ratios $(0<X<0.9)$ when grown in bulk films [28]. The diffraction patterns of $\mathrm{ZnSe}_{1-X} \mathrm{Te}_{X}$ emissive layers clearly deviate from the lattice constant estimated from Vegard's law (Figure 2(b)), indicating that the $\mathrm{ZnSe}_{1-X} \mathrm{Te}_{X}$ spherical quantum well layers are strained to fit into the $\mathrm{ZnSe}$ sublayer. Specifically, in the SQW platform, the lattice mismatch between $\mathrm{ZnSe}$ and $\mathrm{ZnSe}_{0.8} \mathrm{Te}_{0.2}$ emissive layer is suppressed by $55 \%, 49 \%$, and $23 \%$ along (111), (220), and (311) directions compared to the bulk parameters, respectively. The reduction in the lattice mismatch between $\mathrm{ZnSe}$ and $\mathrm{ZnSe}_{1-X} \mathrm{Te}_{X}$ alleviates the lattice stresses at the interface between $\mathrm{ZnSe}$ and $\mathrm{ZnSe}_{1-X} \mathrm{Te}_{X}$ and aids to extend the critical thickness for the defect formation during the SQW NC growth, allowing $\mathrm{ZnSe} / \mathrm{ZnSe}_{1-X} \mathrm{Te}_{X} / \mathrm{ZnSe} \mathrm{SQW} \mathrm{NCs}$ to reach near-unity PL QYs.

The achievable emission window of $\mathrm{ZnSe}_{\mathrm{ZnSe}}$. ${ }_{X} \mathrm{Te}_{X} / \mathrm{ZnSe} S Q W \mathrm{NCs}$ by varying the composition of $\mathrm{ZnSe}_{1-}$ ${ }_{X} \mathrm{Te}_{X}$ and the dimension ranges from blue $(450 \mathrm{~nm}, 2.76 \mathrm{eV})$ to orange $(600 \mathrm{~nm}, 2.07 \mathrm{eV})$, which exceeds that of bulk ZnTe $\left(E_{g, \mathrm{ZnTe}}=2.3 \mathrm{eV}\right)$ (Figure $3(\mathrm{a})$ and Figure S5). The wideranging band gap tunability is attributed to the unusual strong band gap bowing of $\mathrm{ZnSe}_{1-X} \mathrm{Te}_{X}$ [29], which is given by

$$
E_{g, \mathrm{ZnSe}_{1-\mathrm{X}} \mathrm{Te}_{\mathrm{X}}}=X \cdot E_{g, \mathrm{ZnTe}}+(1-X) \cdot E_{g, \mathrm{ZnSe}}-b_{\mathrm{ZnSe}_{1-X} \mathrm{Te}_{X}} \cdot X \cdot(1-X),
$$




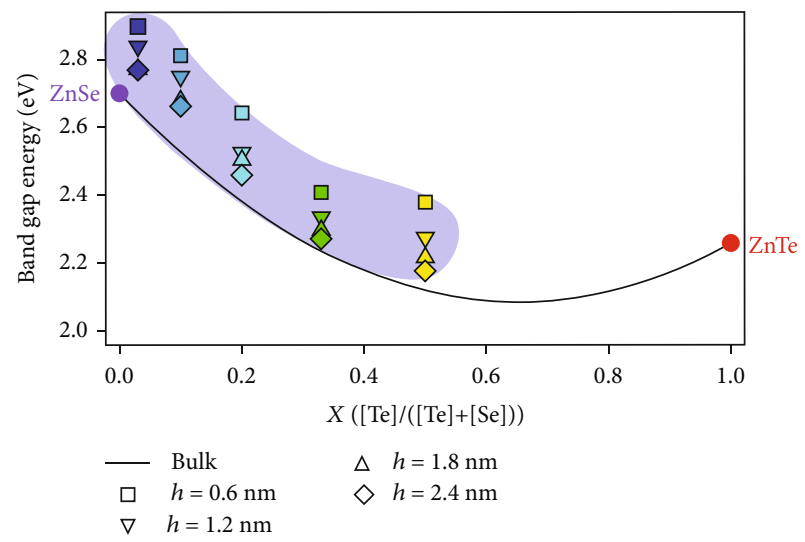

(a)

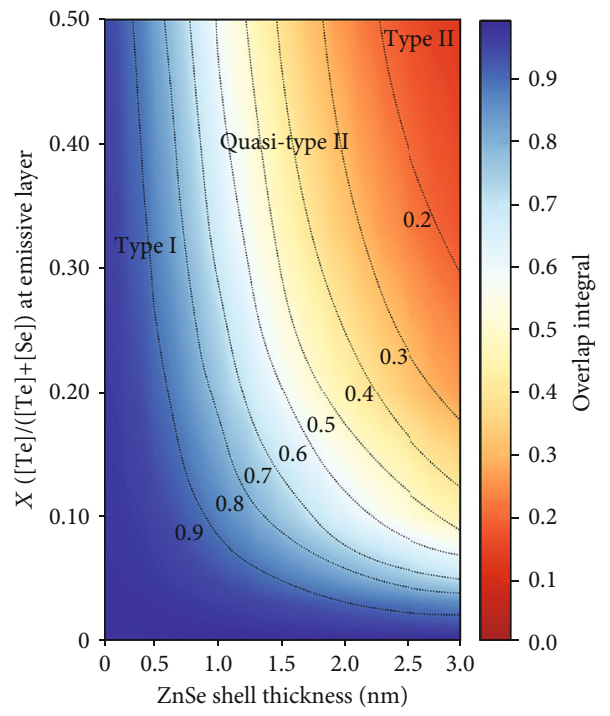

(c)

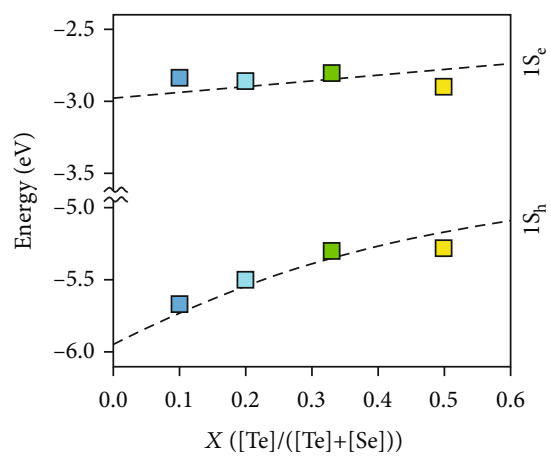

(b)

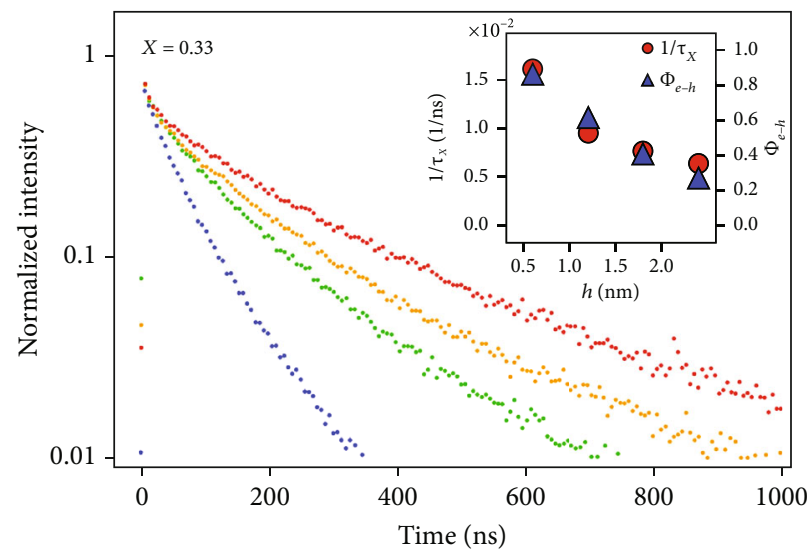

(e)

Figure 3: Electronic features and photophysical properties of $\mathrm{ZnSe} / \mathrm{ZnSe}_{1-X} \mathrm{Te}_{X} / \mathrm{ZnSe} \mathrm{NCs}$. (a) Band gap energy of $\mathrm{ZnSe}_{\mathrm{ZnSe}} \mathrm{Zne}_{X} / \mathrm{ZnSe}$ NCs with varying Te contents $(X=0.03,0.10,0.20,0.33$, and 0.50$)$ and ZnSe shell thicknesses $(h=0.6,1.2,1.8$, and $2.4 \mathrm{~nm})$. The bulk band gap energy of $\mathrm{ZnSe}$ (violet circle at the left $y$ axis) and $\mathrm{ZnTe}$ (red circle at the right $y$ axis) is displayed for comparison. (b) The lowest quantized energy states for electron $\left(1 \mathrm{~S}_{\mathrm{e}}\right)$ and hole $\left(1 \mathrm{~S}_{\mathrm{h}}\right)$ of $\mathrm{ZnSe}(r=0.6 \mathrm{~nm}) / \mathrm{ZnSe}_{1-X} \mathrm{Te}_{X}(l=1.2 \mathrm{~nm}) / \mathrm{ZnSe}(h=0.6 \mathrm{~nm}) \mathrm{NCs}$ with varying Te contents. $1 \mathrm{~S}_{\mathrm{h}}$ and $1 \mathrm{~S}_{\mathrm{e}}$ of NCs are obtained from ultraviolet photoelectron spectroscopy in chorus with UV-Vis absorption spectroscopy. (c) Calculated electron-hole overlap integrals of $\mathrm{ZnSe}(r=0.6 \mathrm{~nm}) / \mathrm{ZnSe}_{1-X} \mathrm{Te}_{X}(l=1.2 \mathrm{~nm}) / \mathrm{ZnSe} \mathrm{NCs}$ with varying Te ratios and ZnSe shell thicknesses. (d) Radial probability of electron and hole wave functions and (e) PL decay dynamics of ZnSe $(r=0.6 \mathrm{~nm}$ )$/ \mathrm{ZnSe}_{0.66} \mathrm{Te}_{0.33}(l=1.2 \mathrm{~nm}) / \mathrm{ZnSe} \mathrm{NCs}$ with varying $\mathrm{ZnSe}$ shell thicknesses $(0.6 \mathrm{~nm} \leq h \leq 2.4 \mathrm{~nm})$. The inset shows radiative decay rates of single exciton $\left(1 / \tau_{x}\right)$ and electron and hole overlap integrals $\left(\Phi_{e-h}\right)$ of each sample. 
where $X$ denotes the Te content in $\mathrm{ZnSe}_{1-X} \mathrm{Te}_{X}$ and $b_{\mathrm{ZnSe}_{1-X} \mathrm{Te}_{X}}$ is the bowing parameter $(1.45 \mathrm{eV})$ [29]. We note that the band gap bowing parameters of $\mathrm{ZnSe}_{1-X} \mathrm{Te}_{X}$ is substantially large compared to the cases with $\mathrm{ZnSe}_{1-X} \mathrm{~S}_{X}$ or $\mathrm{Cd}_{1-X} \mathrm{Zn}_{X} \mathrm{Se}$ alloys $\left(b_{\mathrm{ZnSe}_{1-X} \mathrm{~S}_{X}}=0.41 \mathrm{eV}, b_{\mathrm{Cd}_{1-X} \mathrm{Zn}_{X} \mathrm{Se}}=0.35 \mathrm{eV}\right)$ [30].

The strong band gap bowing could stand for the strong bowing in either the conduction band edge energy level $\left(E_{\mathrm{CBE}}\right)$ or valence band edge energy level $\left(E_{\mathrm{VBE}}\right)$ of $\mathrm{ZnSe}_{1-}$ ${ }_{X} \mathrm{Te}_{X}$ or a combination of both, whose impact to the distribution of electron and hole wave functions and their recombination processes varies significantly. So far, the key parameters (e.g., the band position and the effective masses of charge carriers $\left.\left(m_{e} *, m_{h} *\right)\right)$ for $\mathrm{ZnSe}_{1-X} \mathrm{Te}_{X}$ alloys are largely missing. To gain the band position of $\mathrm{ZnSe}_{1-X} \mathrm{Te}_{X}$ alloy NCs, we conduct spectroscopic analysis on $\mathrm{ZnSe} / \mathrm{ZnSe}_{1-X} \mathrm{Te}_{X} / \mathrm{ZnSe} S \mathrm{SQ}$ NCs in parallel with simulation on bulk $\mathrm{ZnSe}_{1-X} \mathrm{Te}_{X}$ alloys (Figures 3(a) and 3(b) and Table S1). The ultraviolet photoemission spectroscopy (UPS) on $\mathrm{ZnSe} / \mathrm{ZnSe}_{1-X} \mathrm{Te}_{X} / \mathrm{ZnSe} \mathrm{SQW}$ NCs with varying Te ratios allows to measure the quantized energy state of hole $\left(1 \mathrm{~S}_{\mathrm{h}}\right)$, and the UV-Vis spectroscopy enables estimating the quantized energy state of electron $\left(1 \mathrm{~S}_{\mathrm{e}}\right.$ ) (Figure 3(b) and Figure S6). The quantum mechanical calculation in $\mathrm{ZnSe}_{\mathrm{ZnSe}} \mathrm{I}_{-X} \mathrm{Te}_{X} / \mathrm{ZnSe} \mathrm{SQW} \mathrm{NCs}$ allows us to approximate energy positions $\left(E_{\mathrm{CBE}}\right.$ and $\left.E_{\mathrm{VBE}}\right)$ and effective masses of charge carriers for $\mathrm{ZnSe}_{1-X} \mathrm{Te}_{X}$ alloys with varying Te contents. The experimental results show that the unusual band gap bowing of $\mathrm{ZnSe}_{1-X} \mathrm{Te}_{X}$ alloys is a result of the strong bowing of $E_{\mathrm{VBE}}$ of $\mathrm{ZnSe}_{1-X} \mathrm{Te}_{X}$ alloys. In fact, $E_{\mathrm{CBE}}$ of $\mathrm{ZnSe}_{1-X} \mathrm{Te}_{X}$ alloys varies linearly along with $\mathrm{Te}$ contents.

Figure 3(c) displays the overlap integral of $\mathrm{ZnSe}$ $(r=0.6 \mathrm{~nm}) / \mathrm{ZnSe}_{1-X} \mathrm{Te}_{X}(l=1.2 \mathrm{~nm}) / \mathrm{ZnSe} \mathrm{SQW}$ NCs as a function of the Te ratio $(0 \leq X \leq 0.5)$ and the ZnSe shell thickness $(0 \leq h \leq 3.0 \mathrm{~nm})$. The asymmetric changes in $E_{\mathrm{CBE}}$ and $E_{\mathrm{VBE}}$ of $\mathrm{ZnSe}_{1-X} \mathrm{Te}_{X}$ alloys allow constructing quasitype II band alignment across the $\mathrm{ZnSe}$ seed, $\mathrm{ZnSe}_{1-X} \mathrm{Te}_{X}$ emissive layer, and ZnSe shell layer, in which the electron wave function is delocalized over the entire volume, whereas the hole wave function is strongly confined within the $\mathrm{ZnSe}_{1 \text { - }}$ ${ }_{X} \mathrm{Te}_{X}$ emissive layer (Figure $\left.3(\mathrm{~d})\right)$. In a given $\mathrm{ZnSe}(r=0.6 \mathrm{~nm}$ )$/ \mathrm{ZnSe}_{1-X} \mathrm{Te}_{X}(l=1.2 \mathrm{~nm}) / \mathrm{ZnSe}$ geometry, the quantum confinement effect is only valid to electron wave functions and the energy of hole wave function is primarily governed by the composition of the $\mathrm{ZnSe}_{1-X} \mathrm{Te}_{X}$ emissive layer. The chosen variation in the composition $(X)$ of the $\mathrm{ZnSe}_{1-X} \mathrm{Te}_{X}$ emissive layer and the ZnSe shell thickness $(h)$ modulates the energy levels of $1 \mathrm{~S}_{\mathrm{h}}$ and the $1 \mathrm{~S}_{\mathrm{e}}$ of NCs by $0.5 \mathrm{eV}$ and $0.2 \mathrm{eV}$, respectively, and the combination of both enables to engineer the optical band gap of quasi-type II NCs from $2.07 \mathrm{eV}$ to $2.76 \mathrm{eV}$.

The electronic structure of given NCs is similar to the case of quasi-type II heterostructures made of CdSe and CdS, but the variation in electron and hole overlap integral appears to be more dramatic than the case with CdSe and CdS [15]. For example, the growth of the ZnSe shell from $0.6 \mathrm{~nm}$ to $3.0 \mathrm{~nm}$ reduces the electron and hole overlap integral of ZnSe $(r=0.6 \mathrm{~nm}) / \mathrm{ZnSe}_{0.67} \mathrm{Te}_{0.33}(l=1.2 \mathrm{~nm}) / \mathrm{ZnSe}$ SQW NCs from 0.9 to 0.2 , which accompanies the substantial change in the single exciton recombination rate from $0.0161 \mathrm{~ns}^{-1}$ to $0.0064 \mathrm{~ns}^{-1}$ (Figure 3(e)). The wider window to modulate the electron and hole wave functions is important not only because it provides optical band gap tunability of quasi-type II NCs to complement with that of previously reported quasi-type II NCs [15-21], but also because it promises the capability to engineer the multicarrier dynamics of NCs that is the key for realizing nonblinking quantum emitters or high power light sources. Indeed, trion lifetime measurements (Figure S8) indicate that multicarrier dynamics in $\mathrm{ZnSe}(r=0.6 \mathrm{~nm}) / \mathrm{ZnSe}_{0.67} \mathrm{Te}_{0.33}(l=1.2 \mathrm{~nm}$ )/ZnSe/ZnS SQWs are similar to those measured in CdS/CdSe/CdS SQWs [27] and about one order of magnitude slower than the ones reported for regular type I core/shell quantum dots [31].

As a mean to exploit high PL QYs of SQW NCs in a wide range of emission wavelengths, we exemplify dichromatic white NC-based light-emitting diodes (NC-LEDs) by employing the mixed layer of blue- and yellow-emitting $\mathrm{ZnSe} / \mathrm{ZnSe}_{1-X} \mathrm{Te}_{X} / \mathrm{ZnSe} / \mathrm{ZnS} S \mathrm{SQ}$ NCs (Figure 4(a)). Specifically, the dimensions and compositions of blue- and yellowemitting NCs are formulated in ZnSe $(r=0.6 \mathrm{~nm}$ )$/ \mathrm{ZnSe}_{0.97} \mathrm{Te}_{0.03} \quad(l=1.2 \mathrm{~nm}) / \mathrm{ZnSe} \quad(h=0.6 \mathrm{~nm}) / \mathrm{ZnS}$ $(H=0.6 \mathrm{~nm}) \quad$ and $\mathrm{ZnSe} \quad(r=0.6 \mathrm{~nm}) / \mathrm{ZnSe}_{0.50} \mathrm{Te}_{0.50}$ $(l=1.2 \mathrm{~nm}) / \mathrm{ZnSe} \quad(h=0.6 \mathrm{~nm}) / \mathrm{ZnS} \quad(H=0.6 \mathrm{~nm})$, respectively. We adopt an inverted device structure, in which an $\mathrm{NC}$ emissive layer (EML) is sandwiched between hybrid charge transport layers $[6,32]$. In this device structure, the electrons drift from ITO to NCs via $\mathrm{ZnO}$ electron transport layer (ETL), and holes drift from $\mathrm{MoO}_{X} / \mathrm{Al}$ to NCs via the 2,2' -bis(4-(carbazol-9-yl)phenyl)-biphenyl (BCBP) hole transport layer (HTL) (Figure 4(a)). A thin layer of poly $\left[\left(9,9-b i s\left(3^{\prime}\right.\right.\right.$-(N,N-dimethylamino)propyl)-2,7-fluor-

ene)-alt-2,7-(9,9-ioctylfluorene)] (PFN) ( 2 nm) is employed as an interfacial dipole layer to reduce the electron injection barrier between NC EML and ZnO ETL $\left(\Delta E_{\mathrm{CBE}}=1.3\right)$ through the vacuum level shift $(\Delta E=0.3 \mathrm{eV})$ [33]. BCBP with the deep highest occupied molecular orbital $(-5.7 \mathrm{eV})$ serves as the hole transport layer (HTL) for efficient hole injections into both blue- and yellow-emitting $\mathrm{ZnSe} / \mathrm{ZnSe}_{1}$ ${ }_{X} \mathrm{Te}_{X} / \mathrm{ZnSe} / \mathrm{ZnS} \mathrm{SQW}$ NCs.

Figure 4 displays the representative characteristics of dichromatic white NC-LEDs employing a mixed layer of blue- and yellow-emitting $\mathrm{ZnSe} / \mathrm{ZnSe}_{1-X} \mathrm{Te}_{X} / \mathrm{ZnSe} / \mathrm{ZnS}$ SQW NCs. The mixing ratio for blue- and greenemitting NCs is set to be $1: 3$ (wt\%:wt\%) by a process of trial and error (Figure S9). The resulting device displays the peak external quantum efficiency of $1.6 \%$, the peak luminance over $5,000 \mathrm{~cd} / \mathrm{m}^{2}$, and, most importantly, stable white colors upon the variation of operation conditions (Figures 4(b)-4(e)). For practicable use in lighting applications, the brightness in the range of $1,000-5,000 \mathrm{~cd} / \mathrm{m}^{2}$ and high color stability are required $[34,35]$. The performance of present NC-LEDs fully satisfies these criteria in view of the brightness (the peak luminance of $5,700 \mathrm{~cd} / \mathrm{m}^{2}$ ) and the color stability $(\operatorname{CIE} X=0.292-0.315$ and $\operatorname{CIE} Y=0.371-0.41$ at the luminance ranges of $700-5,000 \mathrm{~cd} / \mathrm{m}^{2}$ ). 

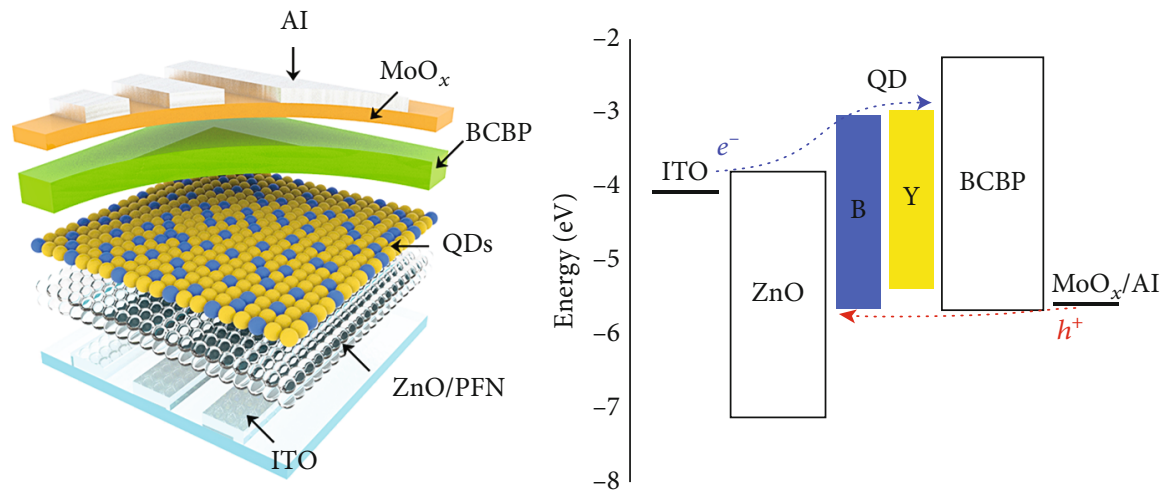

(a)

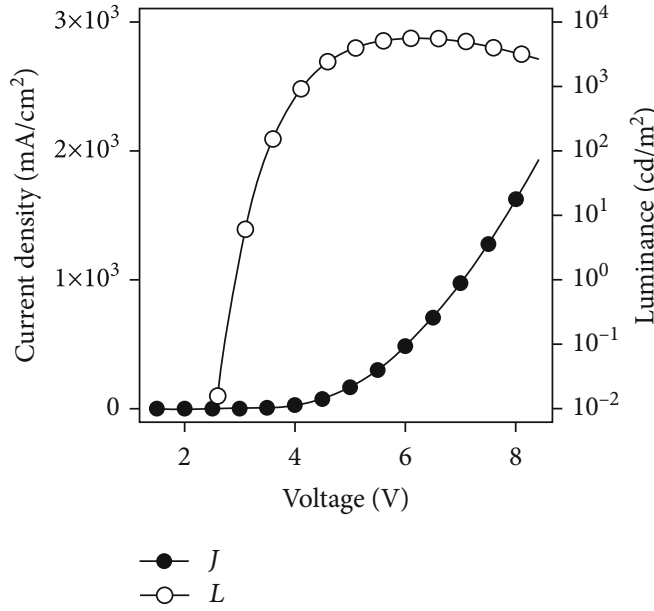

(b)

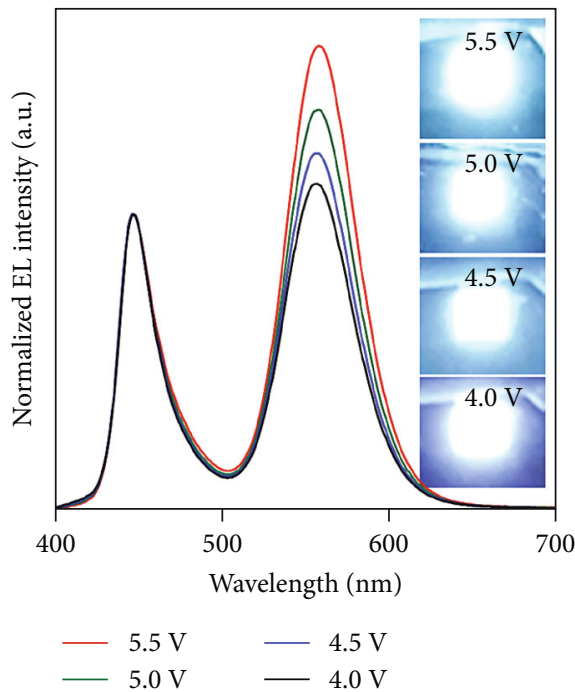

(d)

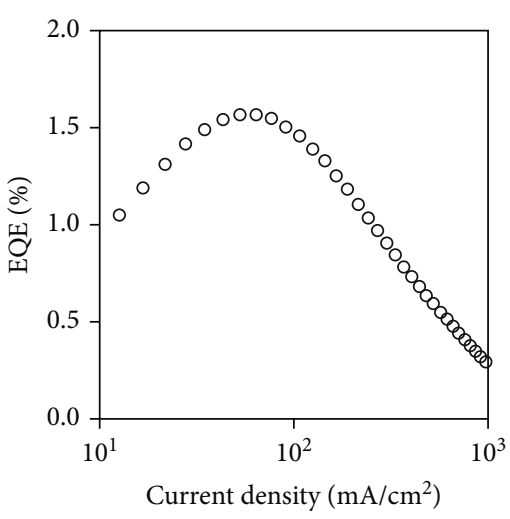

(c)

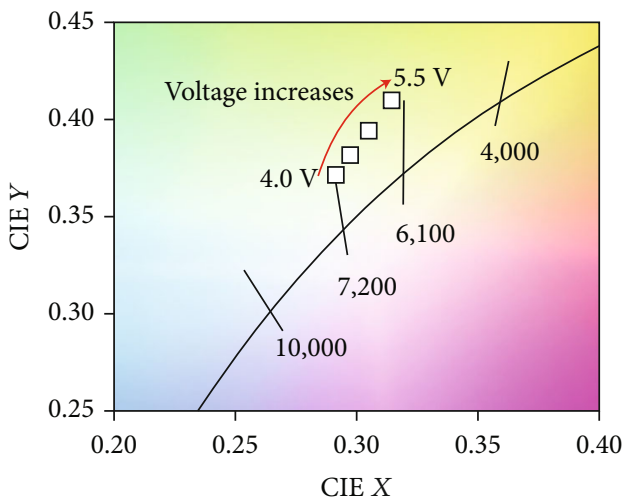

(e)

FIGURE 4: Device characteristics of dichromatic white NC-LED employing blue- and yellow-emitting ZnSe/ZnSe ${ }_{1-X} \mathrm{Te}_{X} / \mathrm{ZnSe} \mathrm{SQW}$ NCs. (a) Schematic illustrations of dichromatic white NC-LED employing blue- and yellow-emitting ZnSe/ZnSe ${ }_{1-X} \mathrm{Te}_{X} / \mathrm{ZnSe} \mathrm{SQW}$ NCs (left) and its energy band diagram (right). (b) Current density-voltage-luminance characteristics and (c) external quantum efficiency (EQE) versus current density of dichromatic white NC-LED. (d) The normalized EL spectra of white NC-LED operated at different applied voltages. (e) The CIE 1931 color space chromaticity diagram demonstrating the color coordinates of EL spectra of white NC-LED operated at different applied voltages. 


\section{Summary}

We have demonstrated highly luminescent quasi-type II heterostructured nanoemitters formulated in $\mathrm{ZnSe}_{\mathrm{ZnSe}}$ ${ }_{X} \mathrm{Te}_{X} / \mathrm{ZnSe}$ seed/spherical quantum well/shell heterostructures. In a given formation of NCs, the electron wave function is delocalized over the entire volume, whereas the hole wave function is strongly confined within the $\mathrm{ZnSe}_{1-X} \mathrm{Te}_{X}$ emissive layer, and thus, the composition of the $\mathrm{ZnSe}_{1-X} \mathrm{Te}_{X}$ emissive layer and the dimension of the ZnSe shell layer permit to tailor the hole and electron wave function independently. The SQW structural platform alleviates large lattice mismatch between the $\mathrm{ZnSe}_{1-X} \mathrm{Te}_{X}$ emissive layer and the ZnSe passivation layer. Benefitting from the capabilities to tune the charge carriers on demand and to form defect-free heterojunctions, resulting $\mathrm{ZnSe} / \mathrm{ZnSe}_{1-X} \mathrm{Te}_{X} / \mathrm{ZnSe} / \mathrm{ZnS}$ SQW NCs show near unity photoluminescence quantum yield (PLQY > 90\%) in a range of emission wavelengths (peak PL from $450 \mathrm{~nm}$ to $600 \mathrm{~nm}$ ), which have not been reached previously. Finally, we exemplify the use of $\mathrm{ZnSe} / \mathrm{ZnSe}_{1-X} \mathrm{Te}_{X} / \mathrm{ZnSe} / \mathrm{ZnS} \mathrm{NCs}$ as the emitters for white light sources.

The supplement of emission wavelengths achieved in the present study completes the emission window for the quasitype II NCs to cover the entire visible region. The apparent next step is to investigate the multicarrier dynamics of $\mathrm{ZnSe} / \mathrm{ZnSe}_{1-X} \mathrm{Te}_{X} / \mathrm{ZnSe} / \mathrm{ZnS}$ SQW NCs in relationship with their structural formulation. In parallel, the delicate design of heterostructures by means of advances in wet-chemistry is required to engineer the multicarrier dynamics in give NCs. These all together will allow engineering the interplay of charge carriers of quasi-type II NCs on demand, hence fostering the use of quasi-type II NCs in a range of lightemitting applications including nonblinking quantum emitters, high power LEDs, or low threshold lasers.

\section{Conflicts of Interest}

The authors declare that there are no conflicts of interest regarding the publication of this article.

\section{Authors' Contributions}

The manuscript was written through contributions of all authors. All authors have given approval to the final version of the manuscript. Jun Hyuk Chang, Hak June Lee, and Seunghyun Rhee contributed equally to this work.

\section{Acknowledgments}

This work was financially supported by the National Research Foundation of Korea (NRF) grant funded by the Ministry of Science, ICT and Future Planning (No. 2020M3H4A1A01086888, No. 2020M3D1A2101319, No. 2020R1A2C2011478, and No. 2019M3D1A1078299), the Ministry of Trade, Industry \& Energy (MOTIE, Korea) (No. 20010737), and the Electronics and Telecommunications Research Institute (ETRI) grant funded by the Korean Government (No. 20ZB1200, Development of ICT Materials,
Components and Equipment Technologies). G.N. and L.A.P. are thankful for the financial support from the Sao Paulo Research Foundation (FAPESP) under the grant No. 2018/15574-6. This research was also in part supported by Samsung Display.

\section{Supplementary Materials}

The Supporting Information is available free of charge on the Energy Material Advances website. Inhomogeneous nucleation of $\mathrm{ZnSe}$ and $\mathrm{ZnTe}$, growth of $\mathrm{ZnSe}_{1-X} \mathrm{Te}_{X}$ emissive layer on $\mathrm{ZnSe}$ seed, absorption and PL spectra of $\mathrm{ZnSe} / \mathrm{ZnSe}_{1-X} \mathrm{Te}_{X}$ $\mathrm{NCs}$, Te contents of $\mathrm{ZnSe} / \mathrm{ZnSe}_{1-X} \mathrm{Te}_{X} \mathrm{NCs}$ in radial direction measured by ICP-AES, absorption and PL spectra of $\mathrm{ZnSe} / \mathrm{ZnSe}_{1-X} \mathrm{Te}_{X} / \mathrm{ZnSe} / \mathrm{ZnS}$ NCs $(r=0.6 \mathrm{~nm} ; l=1.2 \mathrm{~nm} ; h$ $=0.6,1.2$, and $1.8 \mathrm{~nm}$; and $H=0.6 \mathrm{~nm}$ ); lowest quantized electronic energy level of $\mathrm{ZnSe} / \mathrm{ZnSe}_{1-X} \mathrm{Te}_{X} / \mathrm{ZnSe} / \mathrm{ZnS}$ $(r=0.6 \mathrm{~nm}, l=1.2 \mathrm{~nm}, h=0.6 \mathrm{~nm}$, and $H=0.6 \mathrm{~nm})$ measured by UPS, current density (J)-voltage (V)-luminance (L) characteristics of monochromatic NC-LEDs employing $\mathrm{ZnSe} / \mathrm{ZnSe}_{1-X} \mathrm{Te}_{X} / \mathrm{ZnSe} / \mathrm{ZnS}$ NCs $(r=0.6 \mathrm{~nm}, l=1.2 \mathrm{~nm}, h$ $=0.6 \mathrm{~nm}$, and $H=0.6 \mathrm{~nm})$, PL decay dynamics of neutral versus negatively charged $\mathrm{ZnSe} / \mathrm{ZnSe}_{0.67} \mathrm{Te}_{0.33} / \mathrm{ZnSe} / \mathrm{ZnS}$ NCs $(r=0.6 \mathrm{~nm}, l=1.2 \mathrm{~nm}, h=0.6 \mathrm{~nm}$, and $H=0.6 \mathrm{~nm})$, and EL spectra of dichromatic white NC-LEDs depending on blue to yellow ratio. Tables for effective mass of electron and heavy hole depending on Te ratios, device characteristics, and chemical composition profile at the $\mathrm{ZnSe}_{1-X} \mathrm{Te}_{X}$ emissive layer. (Supplementary Materials)

\section{References}

[1] A. I. Ekimov, A. L. Efros, and A. A. Onushchenko, "Quantum size effect in semiconductor microcrystals," Solid State Communications, vol. 56, no. 11, pp. 921-924, 1985.

[2] L. Brus, "Electronic wave functions in semiconductor clusters: experiment and theory," The Journal of Physical Chemistry, vol. 90, no. 12, pp. 2555-2560, 1986.

[3] C. Murray, D. J. Norris, and M. G. Bawendi, "Synthesis and characterization of nearly monodisperse $\mathrm{CdE}(\mathrm{E}=$ sulfur, selenium, tellurium) semiconductor nanocrystallites," Journal of the American Chemical Society, vol. 115, no. 19, pp. 8706$8715,1993$.

[4] V. I. Klimov, Nanocrystal Quantum Dots, CRC Press, 2010.

[5] J. Lim, B. G. Jeong, M. Park et al., "Influence of shell thickness on the performance of light-emitting devices based on $\mathrm{CdSe} / \mathrm{Zn}_{1-\mathrm{X}} \mathrm{Cd}_{\mathrm{X}} \mathrm{S}$ core/shell heterostructured quantum dots," Advanced Materials, vol. 26, no. 47, pp. 8034-8040, 2014.

[6] J. Kwak, W. K. Bae, D. Lee et al., "Bright and efficient full-color colloidal quantum dot light-emitting diodes using an inverted device structure," Nano Letters, vol. 12, no. 5, pp. 2362-2366, 2012.

[7] B. N. Pal, Y. Ghosh, S. Brovelli et al., “'Giant' CdSe/CdS core/shell nanocrystal quantum dots as efficient electroluminescent materials: strong influence of shell thickness on light-emitting diode performance," Nano Letters, vol. 12, no. 1, pp. 331-336, 2011.

[8] F. Meinardi, A. Colombo, K. A. Velizhanin et al., "Large-area luminescent solar concentrators based on 'Stokes-shift- 
engineered' nanocrystals in a mass-polymerized PMMA matrix," Nature Photonics, vol. 8, no. 5, pp. 392-399, 2014.

[9] F. Meinardi, H. McDaniel, F. Carulli et al., "Highly efficient large-area colourless luminescent solar concentrators using heavy-metal-free colloidal quantum dots," Nature Nanotechnology, vol. 10, no. 10, pp. 878-885, 2015.

[10] I. L. Medintz, H. T. Uyeda, E. R. Goldman, and H. Mattoussi, "Quantum dot bioconjugates for imaging, labelling and sensing," Nature Materials, vol. 4, no. 6, pp. 435-446, 2005.

[11] R. Xie, U. Kolb, J. Li, T. Basché, and A. Mews, "Synthesis and characterization of highly luminescent $\mathrm{CdSe}-$ Core $\mathrm{CdS} / \mathrm{Zn}_{0.5} \mathrm{Cd}_{0.5} \mathrm{~S} / \mathrm{ZnS}$ multishell nanocrystals," Journal of the American Chemical Society, vol. 127, no. 20, pp. 7480-7488, 2005.

[12] A. B. Greytak, P. M. Allen, W. Liu et al., "Alternating layer addition approach to CdSe/CdS Core/shell quantum dots with near-unity quantum yield and high on-time fractions," Chemical Science, vol. 3, no. 6, pp. 2028-2034, 2012.

[13] M. A. Hines and P. Guyot-Sionnest, "Synthesis and characterization of strongly luminescing ZnS-capped CdSe nanocrystals," The Journal of Physical Chemistry, vol. 100, no. 2, pp. 468-471, 1996.

[14] V. I. Klimov, A. A. Mikhailovsky, D. McBranch, C. A. Leatherdale, and M. G. Bawendi, "Quantization of multiparticle auger rates in semiconductor quantum dots," Science, vol. 287, no. 5455, pp. 1011-1013, 2000.

[15] F. García-Santamaría, Y. Chen, J. Vela, R. D. Schaller, J. A. Hollingsworth, and V. I. Klimov, "Suppressed Auger recombination in "giant" nanocrystals boosts optical gain performance," Nano Letters, vol. 9, no. 10, pp. 3482-3488, 2009.

[16] C. Javaux, B. Mahler, B. Dubertret et al., "Thermal activation of non-radiative Auger recombination in charged colloidal nanocrystals," Nature Nanotechnology, vol. 8, no. 3, pp. 206-212, 2013.

[17] Y. Chen, J. Vela, H. Htoon et al., ““Giant” multishell CdSe nanocrystal quantum dots with suppressed blinking," Journal of the American Chemical Society, vol. 130, no. 15, pp. 50265027, 2008.

[18] B. Mahler, P. Spinicelli, S. Buil, X. Quelin, J.-P. Hermier, and B. Dubertret, "Towards non-blinking colloidal quantum dots," Nature Materials, vol. 7, no. 8, pp. 659-664, 2008.

[19] C. M. Cirloganu, L. A. Padilha, Q. Lin et al., "Enhanced carrier multiplication in engineered quasi-type-II quantum dots," Nature Communications, vol. 5, no. 1, 2014.

[20] K. Wu, G. Liang+, D. Kong et al., "Quasi-type II CuInS 2 /CdS core/shell quantum dots," Chemical Science, vol. 7, no. 2, pp. 1238-1244, 2016.

[21] C. Wang, X. Tong, W. Wang et al., "Manipulating the optoelectronic properties of quasi-type II CuInS $2 / \mathrm{CdS}$ core/shell quantum dots for photoelectrochemical cell applications," ACS Applied Materials \& Interfaces, vol. 12, no. 32, pp. 36277-36286, 2020.

[22] E.-P. Jang, C.-Y. Han, S.-W. Lim et al., "Synthesis of alloyed ZnSeTe quantum dots as bright, color-pure blue emitters," ACS Applied Materials \& Interfaces, vol. 11, no. 49, pp. 46062-46069, 2019.

[23] H. Asano, S. Tsukuda, M. Kita, S. Fujimoto, and T. Omata, "Colloidal Zn (Te, se)/Zns core/shell quantum dots exhibiting narrow-band and green photoluminescence," ACS Omega, vol. 3, no. 6, pp. 6703-6709, 2018.
[24] S.-H. Lee, C.-Y. Han, S.-W. Song et al., "ZnSeTe quantum dots as an alternative to InP and their high-efficiency electroluminescence," Chemistry of Materials, vol. 32, no. 13, pp. 57685775,2020 .

[25] D. Hahm, D. Ko, B. G. Jeong et al., "Environmentally benign nanocrystals: challenges and future directions," Journal of Information Display, vol. 20, no. 2, pp. 61-72, 2019.

[26] B. G. Jeong, Y.-S. Park, J. H. Chang et al., "Colloidal spherical quantum wells with near-unity photoluminescence quantum yield and suppressed blinking," ACS Nano, vol. 10, no. 10, pp. 9297-9305, 2016.

[27] G. Nagamine, B. G. Jeong, T. A. Ferreira et al., "Efficient optical gain in spherical quantum wells enabled by engineering biexciton interactions," ACS Photonics, vol. 7, no. 8, pp. 2252-2264, 2020.

[28] M. M. el-Nahass, B. Khalifa, A. M. el-Rahman, and R. el-Ariny, "Structural and optical properties of $\mathrm{ZnSe}_{\mathrm{x} \text { Tel-x }}$ solid solutions in thin-film form," Applied Physics A, vol. 63, no. 1, pp. 81-86, 1996.

[29] S. H. Wei and A. Zunger, "Band offsets and optical bowings of chalcopyrites and Zn-based II-VI alloys," Journal of Applied Physics, vol. 78, no. 6, pp. 3846-3856, 1995.

[30] I. Hernandez-Calderon, "Optical properties and electronic structure of wide band gap II-VI semiconductors," in II-VI Semiconductor Materials and Their Applications, pp. 113170, Taylor \& Francis Group, 2018.

[31] L. A. Padilha, W. K. Bae, V. I. Klimov, J. M. Pietryga, and R. D. Schaller, "Response of semiconductor nanocrystals to extremely energetic excitation," Nano Letters, vol. 13, no. 3, pp. 925-932, 2013.

[32] S. Rhee, J. H. Chang, D. Hahm et al., "“Positive incentive” approach to enhance the operational stability of quantum dot-based light-emitting diodes," ACS Applied Materials \& Interfaces, vol. 11, no. 43, pp. 40252-40259, 2019.

[33] J. Lim, M. Park, W. K. Bae et al., "Highly efficient cadmiumfree quantum dot light-emitting diodes enabled by the direct formation of excitons within InP@ ZnSeS quantum dots," ACS Nano, vol. 7, no. 10, pp. 9019-9026, 2013.

[34] J. P. Spindler, J. W. Hamer, and M. E. Kondakova, In White OLED lighting panel manufacturing process, OLEDWorks LLC, 2014.

[35] Y. S. Park, J. W. Kang, D. M. Kang et al., "Efficient, color stable white organic light-emitting diode based on high energy level yellowish-green dopants," Advanced Materials, vol. 20, no. 10, pp. 1957-1961, 2008. 